\title{
PROCEDURAL 3D MODELLING FOR TRADITIONAL SETTLEMENTS. THE CASE STUDY OF CENTRAL ZAGORI
}

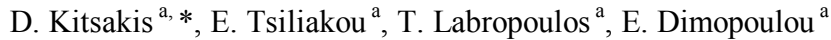 \\ a NTUA, School of Rural and Surveying Engineering, 15780 Zografou, Greece - (dimskit@yahoo.gr; eva.tsiliakos@gmail.com; \\ tassos.labropoulos@gmail.com; efi@survey.ntua.gr )
}

Commission II

KEY WORDS: 3D modelling, procedural modelling, traditional architecture, cultural heritage, Zagori, 3D Cadastre

\begin{abstract}
:
Over the last decades 3D modelling has been a fast growing field in Geographic Information Science, extensively applied in various domains including reconstruction and visualization of cultural heritage, especially monuments and traditional settlements. Technological advances in computer graphics, allow for modelling of complex 3D objects achieving high precision and accuracy. Procedural modelling is an effective tool and a relatively novel method, based on algorithmic modelling concept. It is utilized for the generation of accurate 3D models and composite facade textures from sets of rules which are called Computer Generated Architecture grammars (CGA grammars), defining the objects' detailed geometry, rather than altering or editing the model manually. In this paper, procedural modelling tools have been exploited to generate the 3D model of a traditional settlement in the region of Central Zagori in Greece. The detailed geometries of 3D models derived from the application of shape grammars on selected footprints, and the process resulted in a final 3D model, optimally describing the built environment of Central Zagori, in three levels of Detail (LoD). The final 3D scene was exported and published as 3D web-scene which can be viewed with 3D CityEngine viewer, giving a walkthrough the whole model, same as in virtual reality or game environments. This research work addresses issues regarding textures' precision, $\mathrm{LoD}$ for 3D objects and interactive visualization within one 3D scene, as well as the effectiveness of large scale modelling, along with the benefits and drawbacks that derive from procedural modelling techniques in the field of cultural heritage and more specifically on 3D modelling of traditional settlements.
\end{abstract}

\section{BACKGROUND}

\subsection{Introduction}

Traditional architecture and cultural heritage in terms of traditional buildings, settlements and man-made environment of, inter alia, historical, folkloric, social and aesthetic value, constitute unique characteristics and are protected by international treaties, ratified and implemented through national legislation. In Greece, protection of cultural heritage is provided by the Constitution, implemented by national legislation. Traditional settlements constitute a significant part of Greek cultural heritage. Specifically, 830 settlements have been identified as "traditional settlements" by the Ministry of Environment and Energy (YPEKA), most of which are located in often isolated mountainous or island regions. Statutory legislation for the protection of these settlements is characterised by various malfunctions including institutions with overlapping responsibilities, lacking of systematic organisation of traditional settlements' protection standards and deficient implementation of relative measures. Such deficiencies result in landscape alteration, especially regarding its historic and cultural components, which requires efficient management and protection of traditional architecture and cultural heritage, by means of supporting and promoting traditional settlements that are gradually desolating.

Technological development, especially in the field of computer technology, provides efficient tools that can be exploited in recording and promoting cultural heritage. To this aim, a National Digital Monument Archive project development of National Digital Monument Archive project has been established in order to record and classify heritage and traditional settlements which are under the protection of YPEKA, while a relative project is also conducted by Ministry of Culture and Sports (YPPO). In this direction, this paper aims to provide tools for $3 \mathrm{D}$ visualisation and management of buildings within traditional settlements in digital environment, through the development of procedural modelling rules that exploit in a rapid manner repetitiveness of architectural patterns that constitute the built heritage. Procedural modelling defines the relation between structural and architectural patterns allowing for generation of typical traditional building patterns which, combined, can be used to develop the 3D model of traditional settlements as a whole. To this purpose, procedural modelling techniques are applied to typical traditional buildings in "Kipoi" settlement of municipality of Zagori in Greece. This settlement is declared to be heritage settlement since 1978 (Official Gazette D 594/13.11.1978 and Official Gazette D 615/01.11.1979) comprising characteristic traditional architectural elements such as stone streets, loggias and stone houses.

The paper is structured as follows: Section 2 presents the main characteristics of traditional settlements in Greece, focusing on those of Zagori region in Greece and their unique architecture which is reflected on typical local buildings. Section 3 presents the main features of procedural modelling techniques, while in

\footnotetext{
* Corresponding author
} 
Section 4 application of procedural modelling for generation of part of "Kipoi" settlement in Zagori region is described. In Section 5, conclusions deriving from application of procedural modelling techniques to provide 3D models of traditional settlements are presented, also including the authors' recommendations on exploiting procedural modelling tools for efficient protection, management and promotion of cultural heritage, and especially traditional architecture of isolated settlements.

\subsection{Traditional Settlements and Cultural Heritage}

According to the Ministry of Environment and Energy "Architectural heritage constitutes indispensable expression of cultural heritage wealth, also valuable testimony of our past. Cultural heritage comprises traditional structures, traditional settlements, historic city centres, and man-made environment elements bearing significant historical, architectural, urban design, folklore, social and aesthetic value" (http://www.ypeka.gr). Cultural heritage protection is also constitutionally protected. Specifically, Article 24, § 1, stipulates that "The protection of the natural and cultural environment constitutes a duty of the State. The State is bound to adopt special preventive or repressive measures for the preservation of the environment.", while $\S 6$ provides that "Monuments and historic areas and elements shall be under the protection of the State. A law shall provide for measures restrictive of private ownership deemed necessary for protection thereof, as well as for the manner and the kind of compensation payable to owners.". Legislation regulating protection of cultural heritage comprises over 40 laws, presidential decrees, legislative decrees and ministerial decisions (Panoutsopoulos, 2007). Furthermore, international conventions, treaties, and European Union decisions and directives form the fabric of cultural heritage protection in Greece.

\subsection{Traditional Settlements}

In Greece, there is no legal definition of traditional settlements (Panoutsopoulos, 2007), therefore different stipulations are used to define them such as "... any homogenous set of urban or rural constructions, which requires to be protected by the State, due to its distinct architectural, social, artistic or historical significance" (Papapetropoulos, 2004), or more plainly "Traditional settlement are considered those settlements that have remain unaffected through the years, by maintaining their local characteristics" (www.el.wikipedia.org). A significant number of institutions is responsible for declaring a settlement as traditional, including, inter alia, Ministry of Environment and Climate Change, Ministry of Interior and Ministry of Maritime Affairs, Islands and Fisheries. Currently, about 1000 settlements have been declared as "traditional", mostly comprising settlements traced in mountainous regions and islands (Koudouni, 2014). In order to document the specific architectural characteristics and to define specialised construction rules that reflect local architectural character, a program of compiling the morphological characteristics of construction rules and architecture in each administrative region of Greece was launched in September 2011. This program comprises of 48 regional reports, out of which 28 have been assigned and are in progress.

\subsection{Zagori study area}

Zagori region constitutes a complex of 46 mountainous settlements in the base of mountain Pindos in North-Western Greece, covering around 1000 sq. m. (fig. 1). It is divided in three, non administrative, sub-regions, East, Central and West, based on geographical and socioeconomic criteria. Historically, establishment of settlements in the area dates from 1352 A.C.,

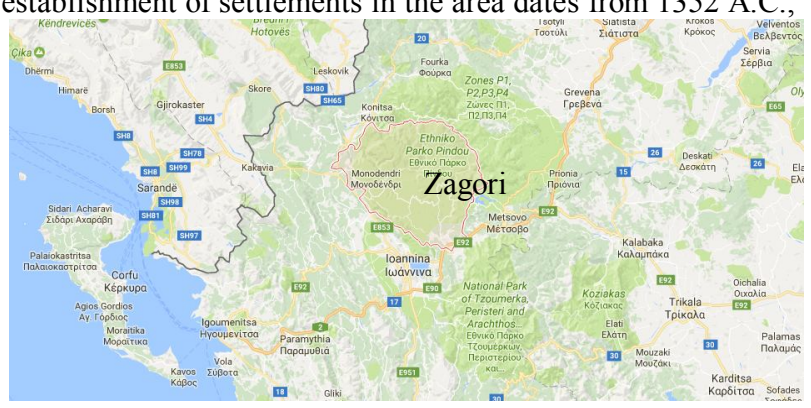

Figure 1. Zagori area

based on byzantine decrees, while since 1678, about 60 settlements had been established in the region (Stamatopoulou, 1999). Although raids in Zagori region were common through the years, invaders did not manage to settle to the area, mostly due to its natural fortification. Specifically, local settlements are organised in neighbourhoods, densely built, in defensive formation around settlement's centre. Similarly, buildings are constructed so as to provide protection both from invaders and bad weather conditions, also considering view, solar exposure and slopes. Buildings comprise of two or three floors, depending on ground slope, as presented in fig. 2, with stone walls and hipped stone roof.

During the years, traditional building typology can be classified in the following types (Stamatopoulou, 1999):

Type A ("grandmother"). Buildings of this type are constructed around 1650. They comprise of an elevated ground-floor, of square or rectangular shape, an exterior stone stairway of 6-10 steps. Buildings are made of dry-stone masonry while wooden parts are made of oak. Currently, only a few buildings of this type remain in the region, while in most cases is has been modified due to alterations during the years.

Type B ("mother"). This type of building dates to $1700-1750$. Its main characteristics are its square shape, including 4 rooms, higher and more spacious compared to previous building type. The house entrance leads to the foyer, type of a ground-floor recessed balcony with arches called "hagiati". A staircase starts in "hagiati", which in this building type, comprises of more steps leading to the floorlanding, "krevatta", open from one or both sides covered by wooden roof.

Type C (“daughter"). This buildings are dated from 1800-1850. In this building type, staircase is made of wood with 4-5 stone first steps. Floorlanding is walled in one either both sides in timberwork. Building's interior is further decorated, while separate spaces for sleeping and guest-rooms are also added, depicting the wealth of each owner.

Buildings of the last type. This building type has been established since 1870-1880. The main 
differences from older types are that floor-landing and recessed balcony are covered by all sides by stone masonry.

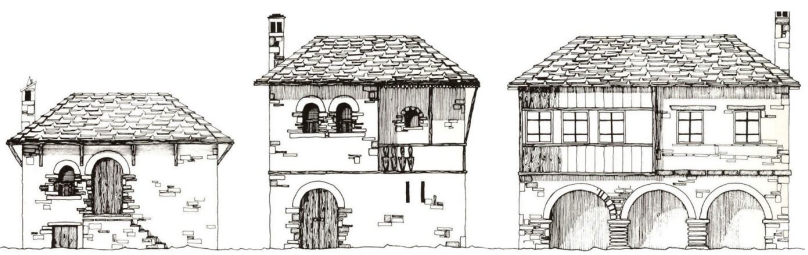

Figure 2. Typical house typology: "grandmother" (left), "mother" (middle), "daughter” (right) (Source: Stamatopoulou, 1999)

\subsection{Kipoi settlement}

Case study area selected is part of the traditional settlement "Kipoi" in Zagori region. The settlement is situated in the western part of Zagori (as presented in fig. 3), in about $800 \mathrm{~m}$. height. According to 2011 census, its population numbers 86 people. Kipoi settlement constitutes one of the first settlements in Zagori, while indications of its establishment date since 1431 A.C. Its significance within Zagori is evident as Kipoi was the capital of Zagori region. The settlement is well-known of its traditional architecture, comprising stone arch bridges and stone paved streets. It has been declared "traditional" since 1979 by Presidential Decree (P.D 1-11-1979 as modified by P.D 20-06-1995), also defining special construction regulations within the area, while a number of Kipoi settlement landmarks are recorded in Ministry of Culture's list of monuments.

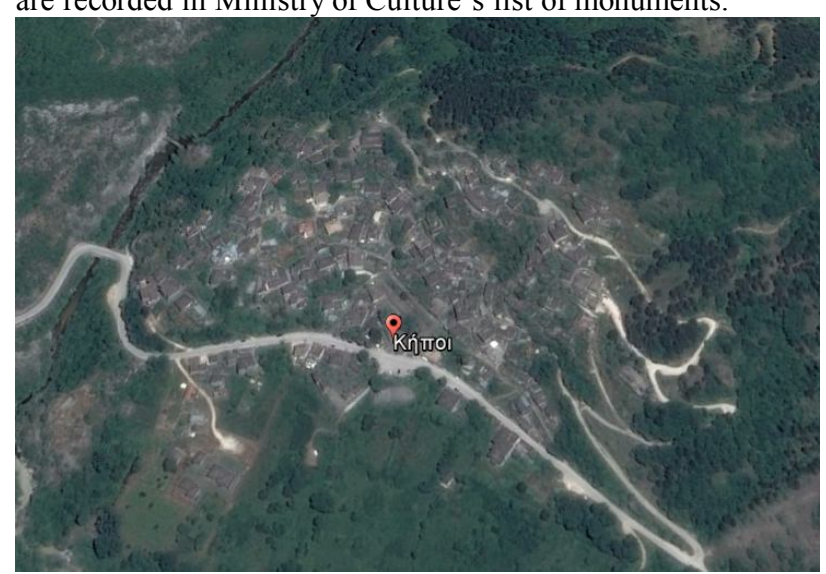

Figure 3. Satellite view of the Kipoi settlement

\section{3D MODELLING IN URBAN LAND MANAGEMENT}

\subsection{D Cadastre}

Efficient management of the complexities deriving from overlapping and interlocking structures within urban environment requires systems of recording, editing, managing and visualising spatial information. Technological development provides tools for cost and time effective acquisition, modelling and management of 3D data, thus leading to optimal exploitation of space, in accordance with the technical, institutional and legal regulations that apply (Dimopoulou, 2016).
According to Stoter and v. Oosterom (2006), 3D Cadastre records and provides insight on the rights and restrictions that apply not only to land parcels but extend to their 3D space. Although development of 3D Cadastre may seem not closely related to traditional, isolated, mountainous or island areas, their relation emerges from Rights, Restrictions and Responsibilities (RRRs) both of Private and Public Law, which are imposed on real property to secure environment, groundwater or traditional architecture protection. Furthermore, spatial information management is also related to parameters including time, accuracy and cost. Integration of such factors to cadastral systems, results in extending from 3D to $\mathrm{nD}$ cadastral systems.

Recording of cultural heritage is of great significance, both for historical reasons and to ensure their protection and proper maintenance. Ministry of Culture and Sports has developed "Odysseus" project in order to record descriptive and geospatial data on archaeological sites, protected areas and immovable monuments in combination with the ongoing Archaeological Cadastre Project. However, there has been provision neither for the recording of traditional settlements, nor for documentation of traditional architecture. This puts traditional settlements in jeopardy, as they are gradually deserted and due to the lack of organised urban development.

\subsection{D Modelling}

Remondino and El-Hakim (2006) define 3D object modelling as the complete process starting from data acquisition to provide a $3 \mathrm{D}$ virtual model, visually interactive on a computer. Technological development in $3 \mathrm{D}$ data acquisition contributes to the extended use of 3D models in various applications such as object documentation, navigation and visualisation. Literature provides a variety of 3D modelling techniques:

Image based rendering that allows for realistic visualisation of $3 \mathrm{D}$ objects and scenes, without requirement of 3D model reconstruction (Chan et al., 2007).

Range based modelling that allows acquisition of a dense 3D point cloud of an object's surface. Point cloud data processing provides the 3D object's model. Such techniques are currently exploited in a variety of applications, while sensors used for 3D data acquisition can be classified in different categories depending on the method of 3D data acquisition, technical characteristics, etc (Kitsakis, 2011).

Combination of image and range based modelling, especially in case of complex architectural objects, exploiting the advantages of each method to provide time effective, high quality 3D models (Remondino and El Hakim, 2006).

Procedural modelling provides generation of 3D building models using sets of rules. Procedural modelling software exploits object grammars to generate $3 \mathrm{D}$ models in various domains such as constructions, simulation, movie industry and video games. Procedural modelling techniques allow for cost effective generation of realistic, 3D complex urban environment models, based on repeated architectural building patterns (Tsiliakou et al, 2014). This technique is further analysed in section 
2.3, while implementation of procedural modelling techniques in generating the 3D model of part of Kipoi settlement in Zagori region is presented in section 2.3.

\subsection{Procedural modelling}

Due to the variety of its areas of application and available techniques, procedural modelling is difficult to be strictly defined. Ebert et al. (2003) (according to Smelik et al. (2014), generically define that procedural modelling provides content through a procedure or a program. Depending on procedural modelling techniques, 3D object models can be generated in an automatic or semi-automatic way. The advantages of this method comprise generation of realistic, 3D models of large scale urban environments which can be achieved even by using images, minimising time and cost required, compared to conventional 3D modelling techniques. Furthermore, procedural modelling rules can be edited by users in order to alter or adjust aspects of generated 3D models, thus allowing to recompose $3 \mathrm{D}$ models of different characteristics from the original ones (e.g. exploitation of images to reconstruct the 3D model of a collapsed building's roof). Relevant literature has been enriched with numerous papers on the reconstruction and documentation of cultural heritage by using procedural modelling techniques, specifically CityEngine (Haegler et al., 2009; Piccoli, 2013; Watson et al., 2008; Maïm et al., 2007; Muller et al., 2005; Müller et al, 2006; Di Angelo et al, 2013; Cappellini et al, 2013; Chrysanthi et al, 2012; Tepavčević \& Stojaković, V, 2012; Pavlidis et al., 2009; Ferschin \& Di Angelo, 2011). Piccoli (2013) has mentioned a number of procedurally generated cultural heritage projects, such as Rome Reborn by Virginia University and Politecnico di Milano, "Apa, an Etruscan from Bologna" by University of Bologna, Portus project by Universities of Southampton and Cambridge and Aquae Patavinae - Montegrotto by University of Padova.

\subsection{ESRI CityEngine Software}

ESRI CityEngine software constitutes one of the most popular procedural modelling software, covering a variety of applications of 3D city, urban or structural environment modelling. Its use in various applications is provided in literature (Dylla et al., 2010; Picolli, 2013), exploit ESRI CityEngine to generate ancient cities 3D models, while Kim and Wilson (2015), focus on indoor and outdoor navigation.

Generation of 3D models involves three steps. It starts by inserting the background or road network of the area. In the next step, building lots and land parcel are defined also followed by definition of building heights. Finally, buildings' characteristics are described through procedural rules. Application of such rules results in 3D urban model, as presented in fig. 4.

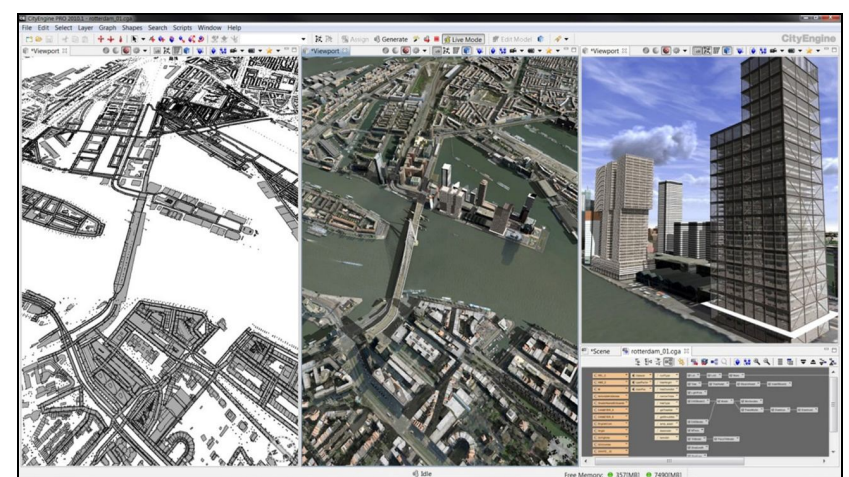

Figure 4. Generation of 3D city model in CityEngine (Source: http://dragons8mycat.com)

\section{APPLICATION OF PROCEDURAL MODELLING TECHNIQUES IN KIPOI SETTLEMENT}

\subsection{Methodology}

This section describes 3D modelling process of part of the traditional settlement "Kipoi", using ESRI CityEngine software. The model is generated from LoD1, comprising only building volumes to LoD2 (textured building volumes including 2D architectural elements) and LoD3 (textured building volumes with $3 \mathrm{D}$ architectural elements, e.g. ledges, arches etc). The process is schematically presented in fig. 5 .

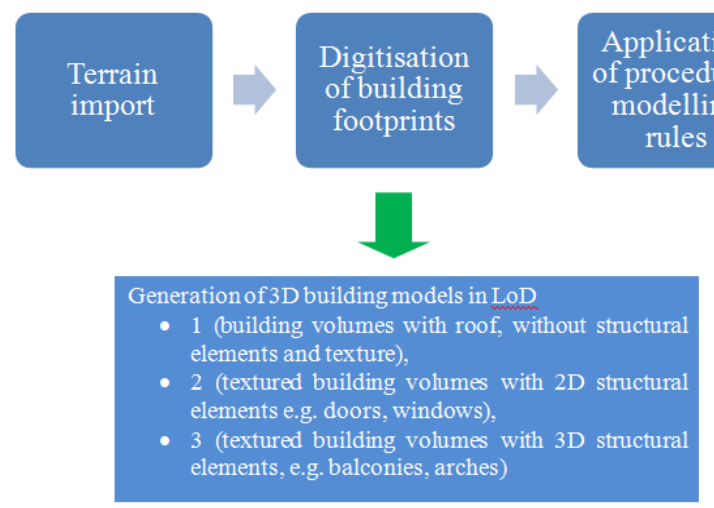

Figure 5. Generation of 3D model - workflow overview

Background on which 3D model is based, comprises combination of Large Scale Orthophotos (LSO) (scale 1:5000) taken from 2007-2009 and Digital Terrain Model (DTM), both acquired by the Greek National Cadastre and Mapping Agency (NCMA).

Building footprints were digitised on LSO, using ESRI ArcGIS software. Given the accuracy of LSO $(0,5 \mathrm{~m})$, protruding structural elements such as balconies were not digitised.

Finally, procedural rules were defined and applied to generate 3D geometries, starting from LoD1 to LoD3. Specifically: 
3.1.1 Generation of LoD1 3D models: LoD1 building models were generated through application of CGA rules, extruding digitised footprints to each building's height. Relative CGA rules have also been applied in order to provide different building heights for each building, as well as to separate each building to its constituent parts (floor, wall and roof surfaces). Part of the extrusion CGA rule along with generated LoD1 model are presented in fig. 6 .
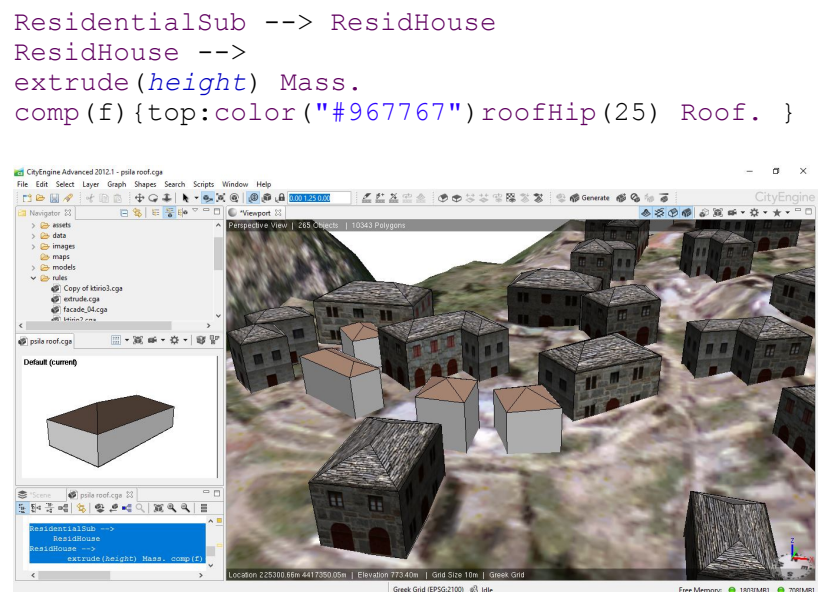

Figure 6. Lod1 models in CityEngine Viewport

3.1.2 Textured LoD2 models: This stage involves 3D model texturing along with adding of 2D structural elements, such as doors and windows. Each model's side is textured by relative CGA rule, while texture data are defined by the user. In this application, texture data involved digital images acquired during visit to the area. Adding of 2D structural elements is similarly implemented based on the separation of the buildings' volumes to their constituent parts. Textured models with added structural elements along with relative CGA rule are presented in fig. 7.

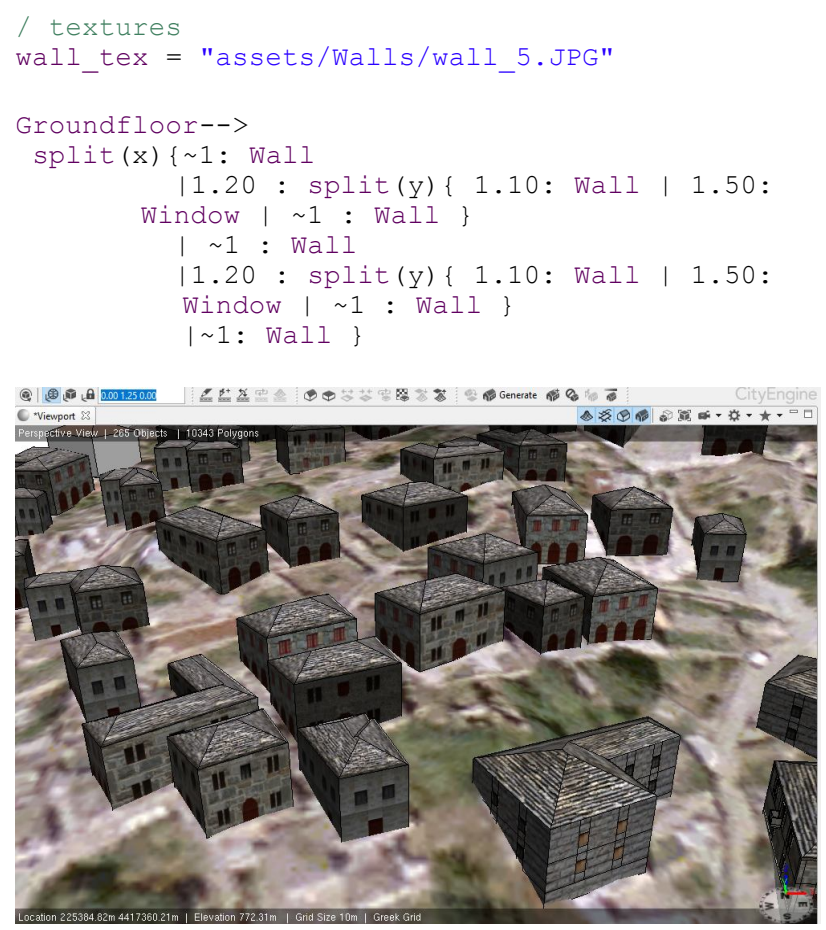

Figure 7. Lod2 models in CityEngine Viewport
3.1.3 LoD3 building models with 3D structural elements: Traditional architecture of Zagori region is characterised by specific architectural elements such as arches, or ledges. Such elements, which can be found in software libraries, are imported in the 3D building models and are adjusted to their specifications while are also assigned textures. Fig. 8, 9, 10, 11 along with relative CGA rules present the generation of $3 \mathrm{D}$ structural elements process, while the final model generated is presented in fig. 12.
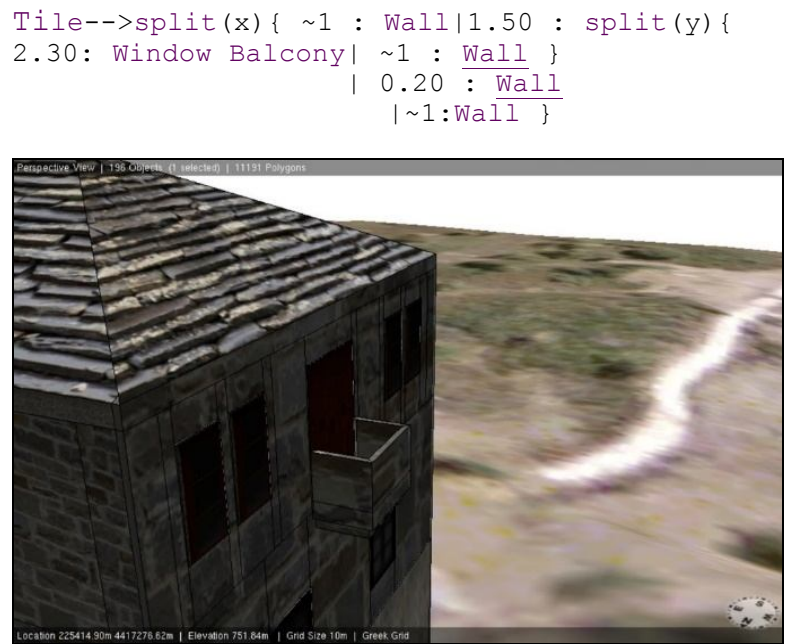

Figure 8. Detail of generated Balcony asset
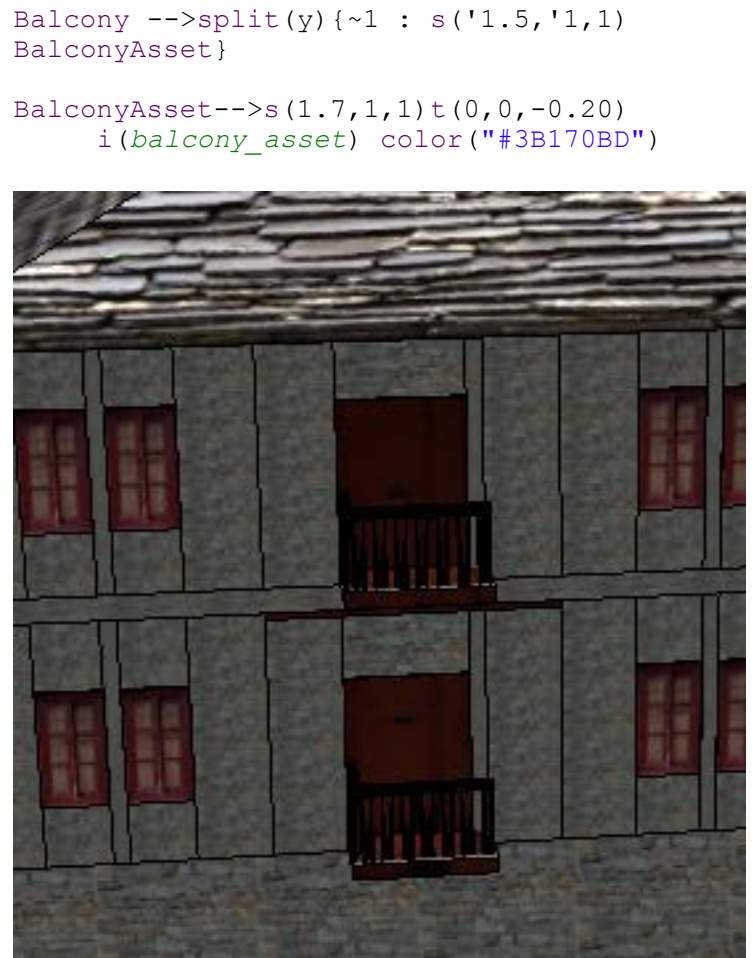

Figure 9. Detail of generated wooden balcony 


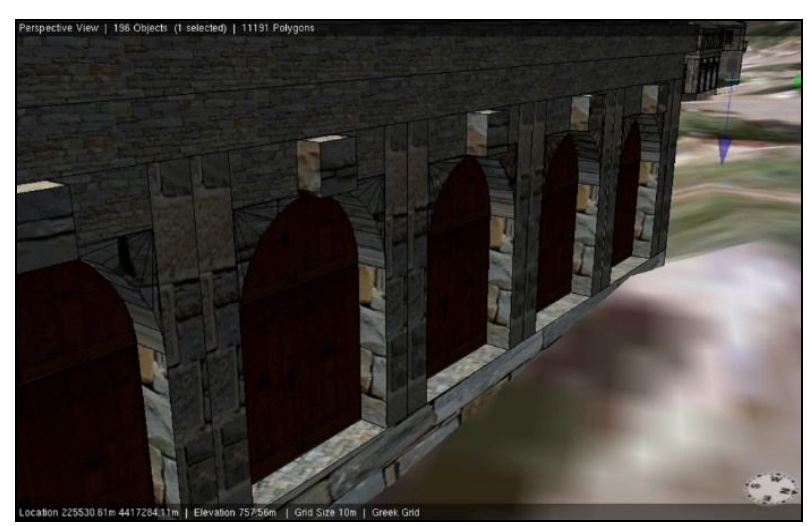

Figure 10. Detail of generated arc

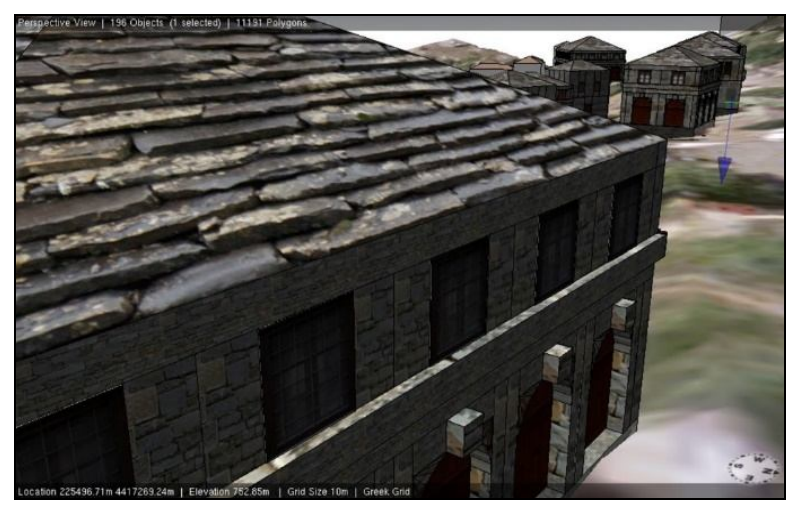

Figure 11. Detail of generated window ledge

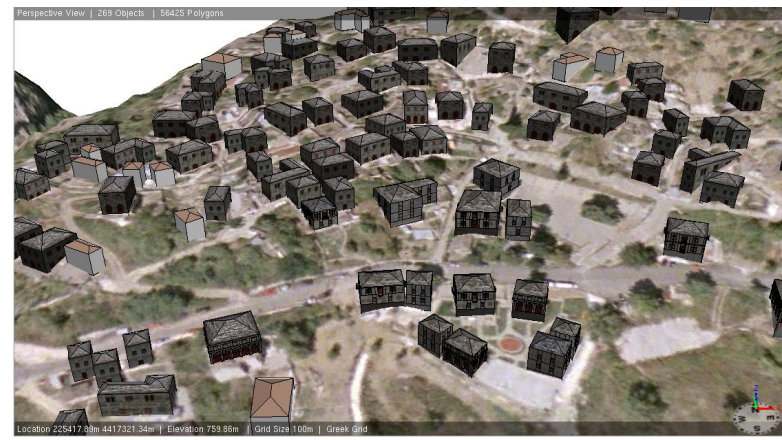

Figure 12. 3D model of the case study area, CityEngine Interface

The 3D models generated can be exported to various file formats to be used to different application areas. In this paper, the whole 3D scene was exported as a File Geodatabase which is compatible with ArcScene by ESRI (fig.12, 13). 3D models thus exported as Multipatch geometries, can be reviewed for a number of applications, such as visibility analysis. The entire scene has also been exported as a 3D web scene in CityEngine Webscene Viewer, which renders 3D geometries and provides better visualization effects on the buildings including sun/daylight and seasonal effects (fig.14, 15, 16).

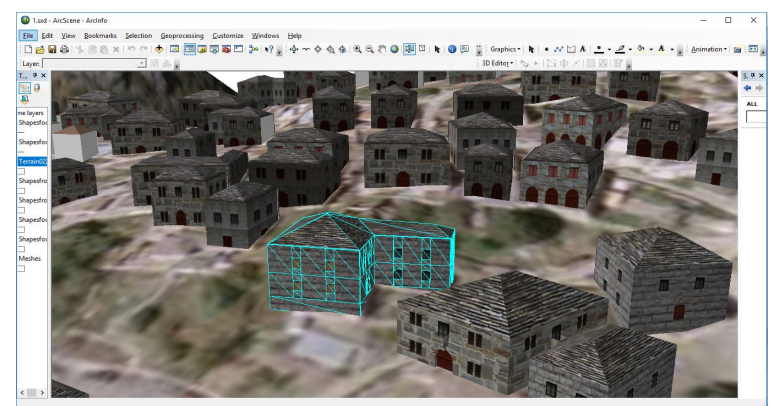

Figure 12. Selection of a building for analysis, ArcScene.

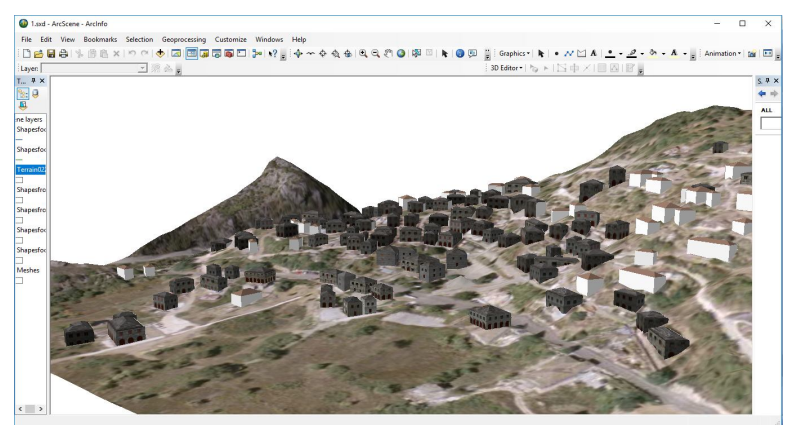

Figure 13. 3D model of the case study area, ArcScene.

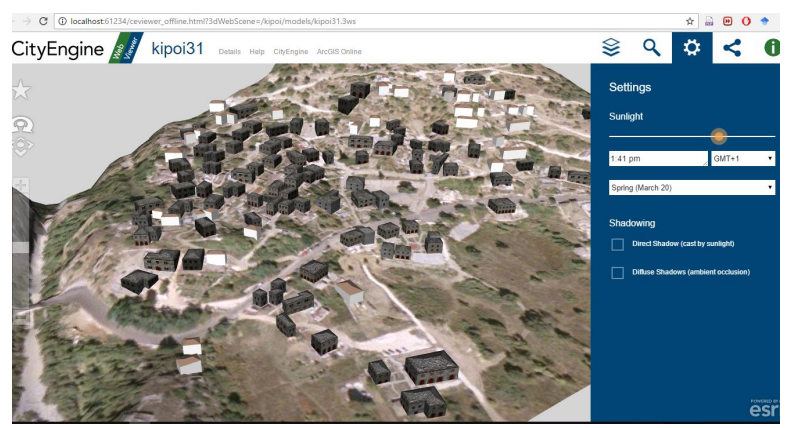

Figure 14. 3D model of the study area, CityEngine Webscene Viewer.

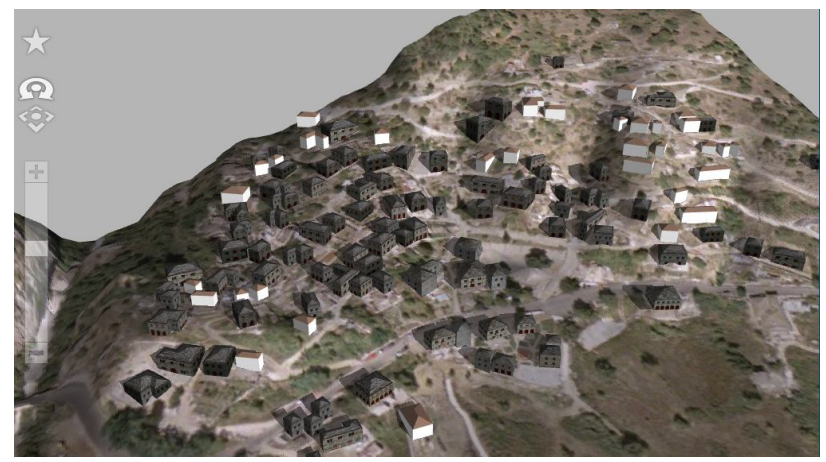

Figure 15. 3D models with shadow effects. 


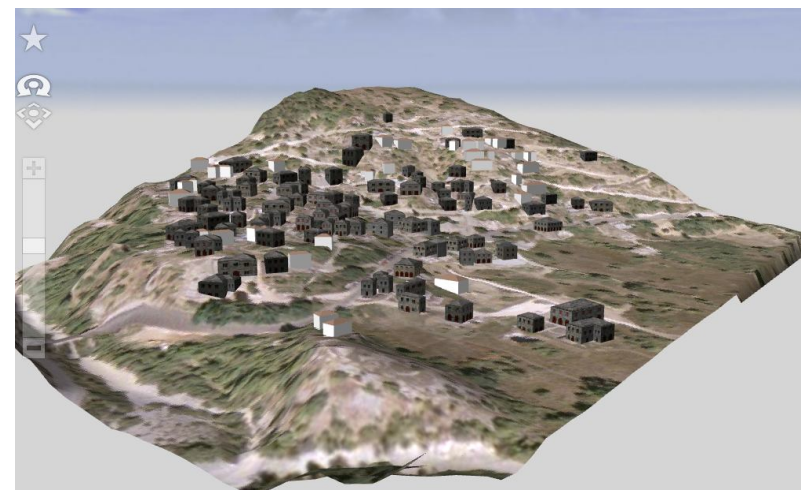

Figure 16. 3D model of the case study area, CityEngine Webscene Viewer.

\section{DISCUSSION - CONCLUSIONS}

Protection of cultural heritage and traditional architecture is highlighted and statutory measures are established and implemented. However, the variety of cultural heritage aspects results in weaknesses protecting all of their expressions. Cultural heritage protection requires significant, both physical and human resources. Furthermore, although there is an extensive legislative fabric protecting cultural heritage, such measures hierarchically focus on monuments and places of archaeological interest, while leaving other expressions of cultural heritage, such as traditional architecture and traditional settlements, in a lower level of legal protection. Relation of traditional settlements and traditional architecture with human activity also constitutes and impediment towards their protection; weather conditions, isolation of rural, and especially mountainous areas due to the lack of infrastructure as well as the high cost of restoration and renovating, leads traditional buildings to desertion.

Modelling traditional settlements by conventional 3D modelling techniques, although facilitated during the years (through advances in 3D data acquisition and management techniques), still requires significant resources, given the extent and required level of detail of the extracted 3D models. Additionally, models deriving from conventional 3D modelling techniques lack semantic characteristics, which allow relations between structural elements of 3D models to be established, facilitating data management and interoperability options. As mentioned in Piccoli (2013) guidelines and principles for computer-based visualisations in cultural heritage are now necessary.

Procedural modelling exploits objects' repetitive patterns to rapidly generate 3D object models in large scale, with limited resources, compared to conventional 3D modelling techniques, which can be further semantically enriched. Procedural modelling supports the creation of "multiple models to convey the uncertainty of the reconstructed archaeological evidence, since variations in shapes can be easily included in the rule file to clarify what is uncertain and what is more precisely documented in the archaeological record' (Piccoli, 2013). For example, Haegler et al. (2009) show 'multiple samples of parts of models with high uncertainty' with the examples of Pompeii and Rome Reborn 2.0 by employing multi-model strategy embedded in one rule file expressing this way 'the relative certainty of different hypotheses'.
Müller et al. (2006) note that 'virtual reconstruction of cultural heritage monuments can not only be based on scanning, but needs to rely on human synthesis of data from multiple and heterogeneous sources' and they further mention that 'procedural modelling rules are an interesting and useful form of knowledge representation for such a synthesis'. On the other hand, 'modelling is generally an open ended problem' (Müller et al., 2006) and procedurally generated models should be extended with further details such as the accuracy offered by photogrammetric models (e.g. the exact positions of building elements, doors etc), or more flexible modeling on fragments by using more parameters.

Nevertheless, CiyEngine offers possibilities such as 'efficient modelling of 3D large environments which are easy to update or to complete 'missing information' areas, easy creation of multiple reconstructions, flexibility, variability and speed of generating buildings and direct connection with gis data' (Piccoli, 2013; Di Angelo, 2013). Since procedural modelling constitutes an effective solution for $3 \mathrm{D}$ models that are characterised by repetitive patterns, in reduced cost, it has been proved also useful in modelling traditional settlements and relative applications, thus facilitating their protection, restoration, documentation, management and promotion.

\section{REFERENCES}

Cappellini, V., Saleri, R., Stefani, C., Nony, N. and De Luca, L., 2013. A procedural solution to model roman masonry structures. International Archives of the Photogrammetry, Remote Sensing and Spatial Information Sciences, 5, p.W2.

Chan, S.C., Shum, H.Y., Ng, K.T., 2007. Image-Based Rendering and Synthesis: Technological advances and challenges. IEEE Signal Processing Magazine, 24(6), pp. 2233 .

Chrysanthi, A., Papadopoulos, C., Frankland, T. and Earl, G., 2012. 'Tangible pasts': user-centred design of a mixed reality application for cultural heritage. Archaeology in the Digital Era, p.31.

Di Angelo, M., Ferschin, P. and Paskaleva, G., 2013, June. Shape Grammars for Architectural Heritage. International Conference on Architecture and Urban Design.

Dylla, K., Frischer, B., Mueller, P., Ulmer, A., and Haegler, S., 2010. Rome Reborn 2.0: A Case Study of Virtual City Reconstruction Using Procedural Modelling Techniques, In: Frischer, B., Webb Crawford, J., and Koller, D. (eds.), Making History Interactive. Computer Applications and Quantitative Methods in Archaeology (CAA). Proceedings of the 37th International Conference, Williamsburg, Virginia, United States of America, March 22-26 (BAR International Series S2079). Archaeopress, Oxford, pp. 62-66.

Ebert D. S., Worley S., Musgrave F. K., Peachey D., Perlin K. : Texturing \& Modeling, a Procedural Approach, $3^{\text {rd }}$ ed. Elsevier, 2003.

Ferschin, P. and Di Angelo, M. 2011. Procedural Modelling of Traditional Balinese Settlements. 
Haegler, S., Müller, P. and Van Gool, L., 2009. Procedural modeling for digital cultural heritage. EURASIP Journal on Image and Video Processing, 2009(1), p.852392.

Kim, H., and Wilson, J.P., 2015. Planning and visualising 3D routes for indoor and outdoor spaces using CityEngine, Journal of Spatial Science, 60(1), pp. 179-193.

Kitsakis, D. 2011. Comparative analysis of photogrammetric methods of 3D data acquisition, Diploma thesis, School of Rural and Surveying Engineering, National Technical University of Athens (in Greek)

Koudouni, A., 2014. Statutory protection of traditional settlements - Overlapping responsibilities, weaknesses in systematising protection criteria and enforcement problems, Conference on "Protection of traditional settlements and modern architectural design", October 11, 2014, Kalamata, Greece (in Greek)

Maïm, J., Haegler, S., Yersin, B., Mueller, P., Thalmann, D. and Van Gool, L., 2007. Populating ancient pompeii with crowds of virtual romans. In Proceedings of the 8th International Symposium on Virtual Reality, Archeology and Cultural Heritage-VAST (No. VRLAB-CONF-2008-151).

Muller, P., Vereenooghe, T., Ulmer, A. and Van Gool, L., 2005, November. Automatic reconstruction of Roman housing architecture. In International Workshop on Recording, Modeling and Visualization of Cultural Heritage (pp. 287297).

Müller, P., Vereenooghe, T., Wonka, P., Paap, I. and Van Gool, L.J., 2006, October. Procedural 3D Reconstruction of Puuc Buildings in Xkipché. In VAST (pp. 139-146).

Panoutsopoulos, N., 2007. Interdepartmental relations in public policies - An example in protection of architectural heritage. Final study, National Centre for Public Administration and Local Government, Athens, Greece (in Greek)

Papapetropoulos, A., 2004. Traditional settlements and cultural environment - Administrative practices and case law. In: Trova, E. (ed.), Proceedings of Conference of European Public Law Organization, 3-4 June, 2003, Sakkoulas publications, Athens-Thessaloniki, pp 647. (in Greek)

Pavlidis, G., Arnaoutoglou, F., Koutsoudis, A. and Chamzas, C., 2009. Virtual Walkthrough in a Lost Town-The Virtual Argostoli. In Proceedings of the IASTED International Conference on Software Engineering, GGIM (pp. 1-5).

Piccoli, C., 2013. CityEngine for Archaeology, Mini conference: 3D GIS for mapping the Via Appia., April 19, 2013, VU University Amsterdam

Remondino, F. and El-Hakim, S., 2006. Image-based 3D Modelling: A Review, The Photogrammetric record, 21(115), pp. 269-291.

Smelik, R., Tutenel, T., Bidarra, R., Benes, B., 2014. A Survey of Procedural Modelling for Virtual Worlds. Computer Graphics Forum 33(6), pp. 31-50.
Stamatopoulou, C., 1991. Greek traditional architecture Volume 6 - Zagori, Melissa publications (in Greek)

Stoter, J. and v. Oosterom. P., 2006. 3D Cadastre in an International Context, CRC Press Taylor and Francis, ISBN 08493-3932-4, pp. 323

Tepavčević, B. and Stojaković, V., 2012. Shape grammar in contemporary architectural theory and design. Facta Universitatis-series: Architecture and Civil Engineering, 10(2), pp.169-178.

Tsiliakou, E., Labropoulos, T. and Dimopoulou, E., 2014. Procedural modelling in 3D GIS environment. International Journal of 3-D Information Modeling (IJ3DIM), 3(3), pp.1734.

Watson, B., Müller, P., Veryovka, O., Fuller, A., Wonka, P. and Sexton, C., 2008. Procedural urban modeling in practice. IEEE Computer Graphics and Applications, 28(3). 